\title{
$\mathbf{M}^{\text {OOURNAL OF }}$ \\ Q CRIALS PROCESSING \\ QU CHARACTERIZATION
}

\section{The effect of AA5083H116 2-layer MIG welding speed on physical and mechanical properties}

\section{Mudjijana* \\ V. Malau \\ U. A. Salim}

Department of Mechanical and Industrial Engineering, Faculty of Engineering, Universitas Gadjah Mada. Jl. Grafika 2, Yogyakarta 55281, Indonesia

Email:

*mudjijana@ugm.ac.id

\section{Keywords}

AA5083H116, ER5356, 2-layer MIG (metal inert gas), welding speed, physical and mechanical properties.

\begin{abstract}
Metal welding can be performed on 1 layer or more depending on the thickness of the plate welded. In the case of 3-mm-thick plates, high-efficiency welding can be carried out on 1 layer if appropriate welding speed, voltage, and amperage are applied. If two layers are to be used, sound weld of 3-mm-thick plates can be achieved if higher welding speed and lower voltage and amperage are applied. This research was intended to conduct 2-layer MIG weld works at welding speeds of $\geq 10,13$, and $16 \mathrm{~mm} / \mathrm{s}$ in accordance with previous research studies and to analyze the physical and mechanical properties generated. This research employed the AA5083H116 material, ER5356 electrode, and argon gas. During the welding processes, the thermal cycles were recorded, and after the processes, the welding results were observed for the macro- and microstructures and for the optimal welding speed under an SEM. In addition, tensile tests, Vickers microhardness tests, and corrosion tests were also undertaken. The results show that the 2-layer MIG welding at the welding speed of $10 \mathrm{~mm} / \mathrm{s}$ produced the best physical and mechanical properties.
\end{abstract}




\section{Introduction}

Welding works are commonplace in the construction sector. With the development of manufacturing process, it is important that welds be carried out in maximum efficiencies. Welding technology is continuously developed to achieve better time and production cost effectiveness. In the transportation sector, specifically, welding applications are ubiquitous in shipping, aviation, and rail transport industries. The materials used can range from carbon steels, aluminum alloys, to stainless steels and a range of other materials. It is imperative to welding constructions that attention be given to the compatibility between the types of materials welded, welding electrodes, and welding methods in order to attain sound welds. A 5083 aluminum alloy is a lightweight metal with a low density of $4.5 \mathrm{~g} / \mathrm{cm} 3$ (Ashby and Jones, 2012). This material is popular owing to its high tensile strength and corrosion resistance. Yazdipour et al. (2011) conducted an inquiry on MIG welding of AA5083 with a variety of parameters, including welding speeds of $7.24-10 \mathrm{~mm} / \mathrm{s}$, voltages of $18-22 \mathrm{~V}$, and electrical currents of 120-182 A, and yielded a maximum ultimate tensile strength value of $337 \mathrm{MPa}$. Kim et al. in their research (2010) obtained from conventional MIG welding of AA5083H116 a tensile strength value of $344.64 \mathrm{MPa}$ in weld metal, which was higher than that in the base metal, with an efficiency of $85.8 \%$. In a separate study, Li et al. (2017) conducted MIG welding with the ER5356 electrode on two dissimilar metals, 7N01-T5 and 7N01-T4, at varied welding speeds of $6.5,7.5$, and $8 \mathrm{~mm} / \mathrm{x}$, electrical current of $290 \mathrm{~A}$, and voltage of $27 \mathrm{~V}$. From that research, they obtained weld-zone tensile strength of $283 \mathrm{MPa}$, which was lower than that in the $\mathrm{BM}$ area $(360 \mathrm{MPa}$ for $7 \mathrm{~N} 01-\mathrm{T} 5$ and $432 \mathrm{MPa}$ for $7 \mathrm{~N} 01-\mathrm{T} 4)$. From the results of the corrosion test on the $4.0 \mathrm{M} \mathrm{NaCl}+0.5$ $\mathrm{M} \mathrm{KNO3}+0.1 \mathrm{M} \mathrm{HNO} 3$ solution medium it was found that 7N01-T4 was more susceptible to corrosion than 7N01-T5. The part most prone to corrosion was the heat affected zone (HAZ), and in general, the weld metal was more susceptible to corrosion than the base metal. Mudjijana et al. (2017) performed characterization of welds of the AA5083H116 material with the ER5356 electrode at varied MIG welding speeds of 8 , 10 , and $12 \mathrm{~mm} / \mathrm{s}$. It was discovered that at the welding speed of $10 \mathrm{~mm} / \mathrm{s}$, the highest tensile strength, bending strength, and welding efficiency were achieved. The results of the studies above can be used as a reference for determination of welding speed for 2-layer MIG welding, with an assumption that the heat generated would be higher than that from 1-layer MIG welding. Thus, it was assumed that the 2-layer MIG welding speed should be faster than that applied in 1-layer MIG welds. This research investigated the effect of ER5356-electrode AA5083H116 2-layer MIG welding speeds (in this study 10, 13, 16 $\mathrm{mm} / \mathrm{s})$.

\section{Materials and Methods}

The material used in this research was AA5093H116 $300 \mathrm{~mm} \times 75 \mathrm{~mm} \times 3 \mathrm{~mm}$ in size, the electrode used was the ER5356 electrode (ASME, 2001) $0.8 \mathrm{~mm}$ in diameter, and the shielding gas used was argon. The welding was undertaken on 2 layers with a Tenjima 200S under the scheme provided in Figure 1 with the welding parameters presented in Table 1. During the welding processes, the thermal cycles were measured with type-K thermocouple wire and an NI USB-9162 instrument in the installation position shown in Figure 2. The welding results were subjected to microstructure observations with a $10 \% \mathrm{NaOH}$ etching solution (AST, 2015), Vickers microhardness tests with a $100 \mathrm{~g}$ load, tensile tests per the ASTM-E8 standard, and corrosion tests with potentiodynamic polarization as shown in Figure 3 within a $3.5 \% \mathrm{NaCl}$ environment with a specimen thickness of $\sim 2 \mathrm{~mm}$ and diameter of $\sim 15 \mathrm{~mm}$. The best welding speed was observed under an SEM (scanning electron microscope). 


\begin{tabular}{ll}
\hline \multicolumn{2}{c}{ Table 1. Welding parameters } \\
\hline \multicolumn{2}{c}{ Welding parameters } \\
\hline $\begin{array}{l}\text { Electrode distance from } \\
\text { specimen (mm) }\end{array}$ & 10 \\
Welding speed (mm/s) & 10,13 , and 16 \\
Welding angle $\left(\theta^{\circ}\right)$ & 80 \\
Average welding voltage & 19 \\
$\begin{array}{l}\text { Volt) } \\
\text { Average welding current } \\
\text { (Ampere) }\end{array}$ & 110 \\
$\begin{array}{l}\text { Filler rate (mm/s) } \\
\text { Filler diameter (mm) }\end{array}$ & 27 \\
$\begin{array}{l}\text { Argon flow } \\
\text { (liter/minute) }\end{array}$ & 0.8 \\
Welding 1-2 pause time \\
(s)
\end{tabular}

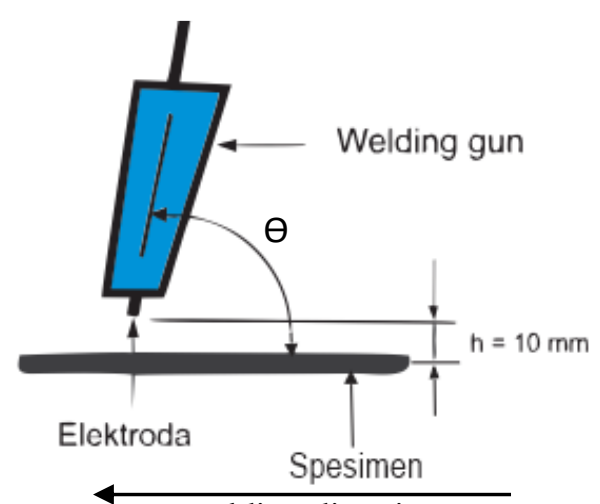

Welding direction

Figure 1. Schematic of welding gun position relative to specimen

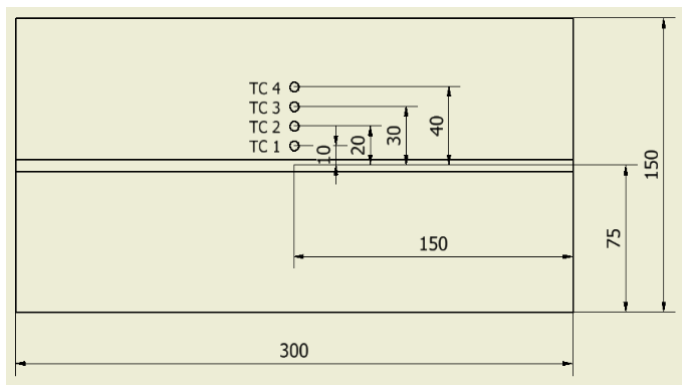

Figure 2. Thermocouple position in specimen

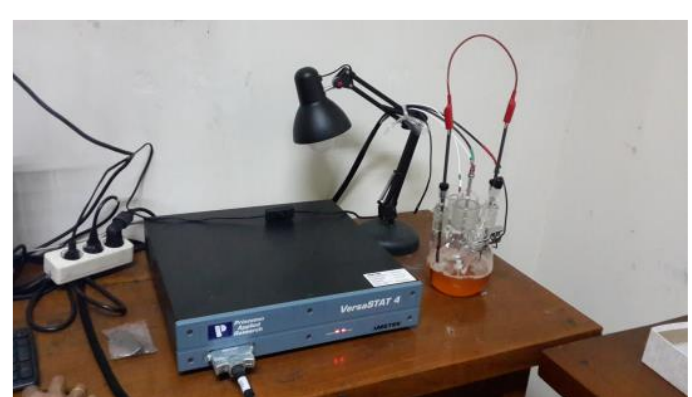

Figure 3. Potentiodynamic polarization corrosion test instrument

\section{Results and Discussion}

\section{Thermal cycle}

Detailed results of the thermal cycle measurement during the welding processes are only provided for the best welding speed of $10 \mathrm{~mm} / \mathrm{s}$ in Figure 4, while the peak temperatures are presented in Table 2. A sample welding joint generated at the welding speed of $13 \mathrm{~mm} / \mathrm{s}$ is displayed in Figure 5. The peak TC1 temperatures on layers 1 and 2 at the welding speeds of 10,13 , and $16 \mathrm{~mm} / \mathrm{s}$ are provided in Table 3 . It is shown in the table that the peak temperatures on layer 1 were lower than those on layer 2 because layer 2 had been affected by the initial heating during the welding processes on layer 1 with a pause time of $10 \mathrm{~mm} / \mathrm{s}$. The peak temperatures at the welding speed of $10 \mathrm{~mm} / \mathrm{s}$ were higher than the rest due to bigger heat input based on the equation $\mathrm{Q}=V I / v$, where $\mathrm{v}$ is welding speed $(\mathrm{mm} / \mathrm{s}), \mathrm{V}$ is welding voltage (Volt), and I is welding current (Amp).

Table 2. Thermal cycle peak temperatures $10 \mathrm{~mm}$ from weld line

\begin{tabular}{ccc}
\hline \multirow{2}{*}{$\begin{array}{c}\text { Welding } \\
\text { speed }\end{array}$} & \multicolumn{2}{c}{ Temperature $\left({ }^{\circ} \mathrm{C}\right)$} \\
\cline { 2 - 3 } & $\begin{array}{c}\text { TC1 peak } \\
\text { temperatures } \\
\text { on layer } 1\end{array}$ & $\begin{array}{c}\text { TC1 peak } \\
\text { temperatures } \\
\text { on layer } 2\end{array}$ \\
\hline $10 \mathrm{~mm} / \mathrm{s}$ & 231.2 & 244.9 \\
$13 \mathrm{~mm} / \mathrm{s}$ & 215.6 & 241.5 \\
$16 \mathrm{~mm} / \mathrm{s}$ & 159.7 & 183.4 \\
\hline
\end{tabular}


Table 3. Peak temperatures in Figure 4

\begin{tabular}{ccccc}
\hline \multirow{2}{*}{ Specimen } & \multicolumn{4}{c}{ Peak temperatures $\left({ }^{\circ} \mathrm{C}\right)$} \\
\cline { 2 - 5 } & TC1 & TC2 & TC3 & TC4 \\
\hline Welding & 231.2 & 151.1 & 109.5 & 97.4 \\
\cline { 2 - 5 } $\begin{array}{c}\text { speed of 10 } \\
\text { mm/s }\end{array}$ & 244.9 & 172.1 & 133.5 & 120 \\
& & & &
\end{tabular}

\section{Macro- and micro observation}

Macrostructure observation was carried out under a $10 \times$ magnitude optical microscope $(\mathrm{OM})$, and the microstructure observation a $200 \times$ magnitude optical microscope. The macrostructure observation results in Figure 6 show the differences between the weld zones of base metal (BM), heat affected zone (HAZ), and weld metal (WM). The weld metal was rich in porosity in all specimens. Porosity is a weld defect from the presence of entrapped solved hydrogen during the welding process in the molten metal, where the molten metal freezes before the hydrogen gets to evaporate. It could also be observed that the specimen welded at the speed of $16 \mathrm{~m} / \mathrm{s}$ experienced incomplete penetration, which is presumed to happen due to a number of factors, namely excessively low welding current, excessively fast welding speed, improper torch angle, and poor welding preparation.

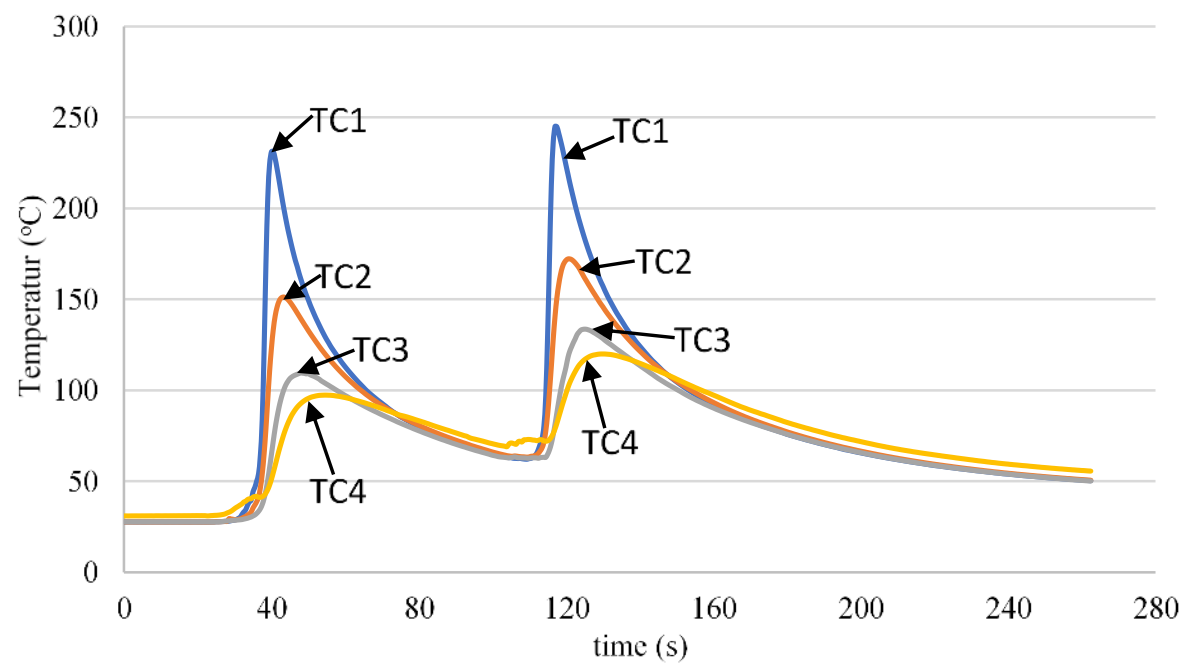

Figure 4. Thermal cycles at welding speed of $10 \mathrm{~mm} / \mathrm{s}$

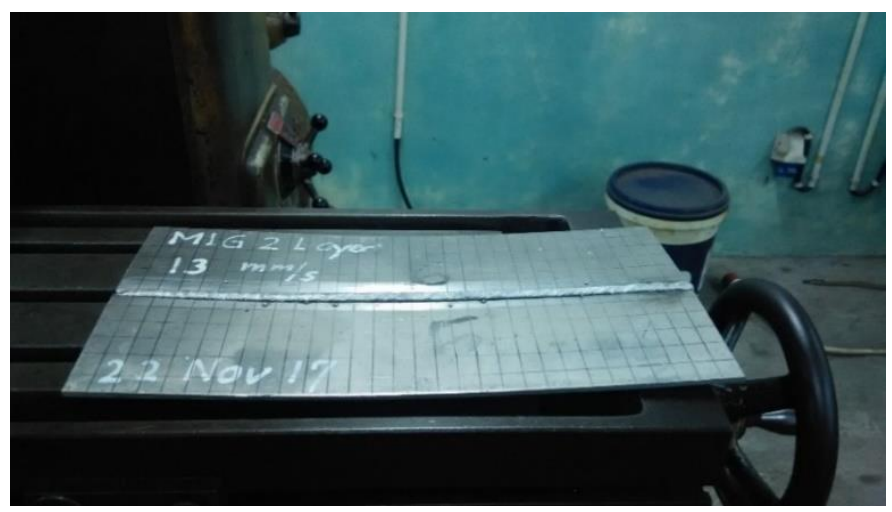

Figure 5. Welding result at welding speed of $13 \mathrm{~mm} / \mathrm{s}$ 


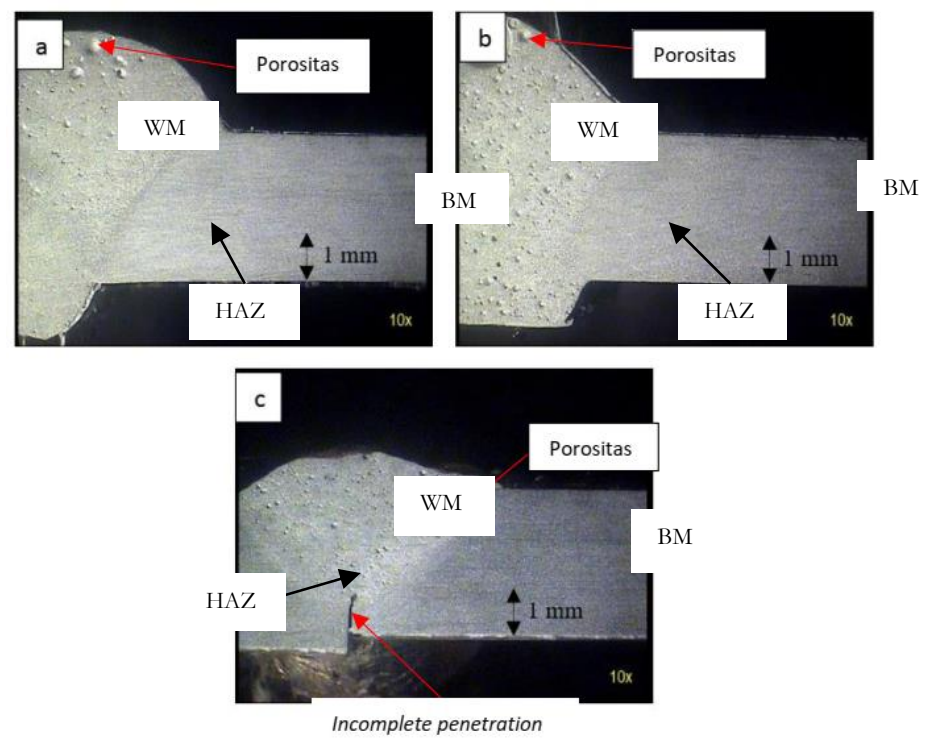

Figure 6. Sectional macrostructure at welding speeds: (a) $10 \mathrm{~mm} / \mathrm{s}$, (b) $13 \mathrm{~mm} / \mathrm{s}$, and (c) $16 \mathrm{~mm} / \mathrm{s}$

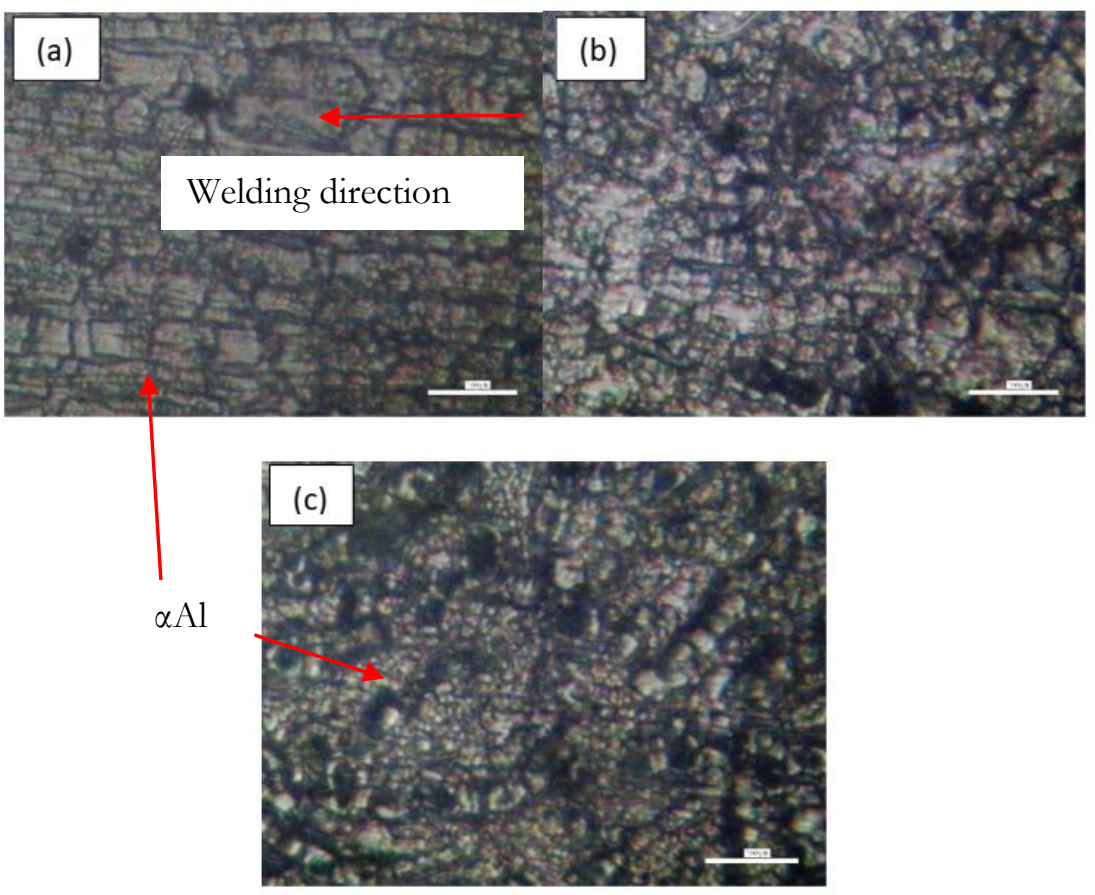

Figure 7. Macrostructure in (a) base metal (BM), (b) heat affected zone (HAZ), and (c) weld metal (WM) at welding speed of $10 \mathrm{~mm} / \mathrm{s}$. 


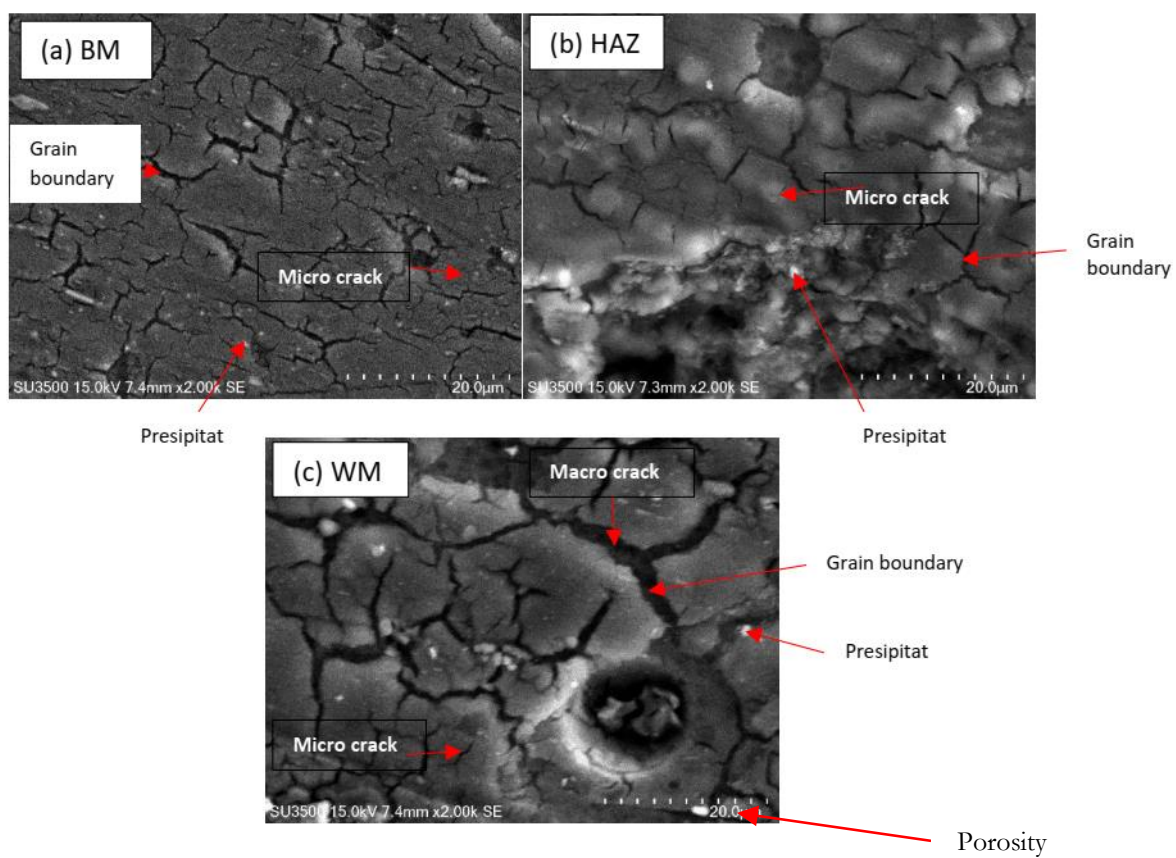

Figure 8. Microstructure under scanning electron microscope (SEM): (a) BM, (b) HAZ, and (c) WM

Microstructure imaging was performed in three different regions, namely base metal (BM), heat affected zone (HAZ), and weld metal (WM), and only the images for the welding speed of $10 \mathrm{~mm} / \mathrm{s}$ are displayed because the microstructures at the other welding speeds were similar with distinction only in the grain size. The grain size at the welding speed of $10 \mathrm{~mm} / \mathrm{s}$ was bigger than those at the welding speeds of 13 and 16 $\mathrm{mm} / \mathrm{s}$ owing to larger heat input. The results of the microstructure observation at the welding speed of $10 \mathrm{~mm} / \mathrm{s}$ are shown in Figure 7. As exhibited in Figure 7(a), the microstructure in the $\mathrm{BM}$ had elongated grains from fabrication with $\mathrm{H} 116$ treatment. The $\mathrm{BM}$ microstructure was unaffected by the heat produced by the welding process. The HAZ microstructure shown in Figure $7(\mathrm{~b})$ had grains partially similar to those in the $\mathrm{BM}$ and partially equiaxed due to WM-BM fusion. Meanwhile, the microstructure in the WM region was almost entirely equiaxed. The $\alpha \mathrm{Al}$ appeared white in color for an Al-Mg alloy with an $\mathrm{Mg}$ content for AA5083H116 of roughly $4.5 \%$.
The results of the SEM microstructure observation at the welding speed of $10 \mathrm{~mm} / \mathrm{s}$ are shown in Figure 8 ((a) BM, (b) HAZ, (c) WM). From the SEM results, it can be observed that the grains in the $\mathrm{BM}$ were smaller in size than those in the HAZ and WM due to H116 treatment. In the HAZ, the granular sizes were slightly bigger than those in the BM, yet slightly smaller than those in the WM, from heat influence over the welding process. On the other hand, the WM had grains in the largest sizes and in equiaxed shapes; the WM was the ER5356 welding material with air cooling-freezing rate. Microcracks and precipitates were spotted in all the BM, HAZ, and WM. Microcracks in the BM emerged because the H116 treatment performed involved solid solution treatment and rolling up to $3 / 4$ hardness. The microcracks in the HAZ were caused by uneven cooling process and non-uniform fusion zone unlike the BM. Meanwhile, the microcracks in the WM were brought about by both small and big grain sizes which caused imbalance in the cooling rate. It is noticeable 
at the granular boundary that more macrocracking took place than microcracking.

\section{Vickers hardness}

Based on Figure 9, Table 3, and Figure 10, the hardness values in the BM from the testing were virtually uniform across the three specimens. The specimen for the welding speed of $10 \mathrm{~mm} / \mathrm{s}$ yielded an average hardness value of $94.07 \mathrm{VHN}, 13 \mathrm{~mm} / \mathrm{s} 93.10$ VHN, and $16 \mathrm{~mm} / \mathrm{s} 93.79 \mathrm{VHN}$. The average hardness value in the HAZ was the highest in the $16 \mathrm{~mm} / \mathrm{s}$ welding speed specimen, namely $92.21 \mathrm{VHN}$. In the $13 \mathrm{~mm} / \mathrm{s}$ welding speed specimen the average value was $83.11 \mathrm{VHN}$, while $10 \mathrm{~mm} / \mathrm{s} 77.34 \mathrm{VHN}$. The WM did not exhibit any significant difference in the hardness value between welding speeds. The specimen for the welding speed of $16 \mathrm{~mm} / \mathrm{s}$ had the highest average hardness value of $72.96 \mathrm{VHN}$, followed by those for the welding speeds of $13 \mathrm{~mm} / \mathrm{s}$ and $10 \mathrm{~mm} / \mathrm{s}$ with 70.94 VHN and 69.84 VHN, respectively.

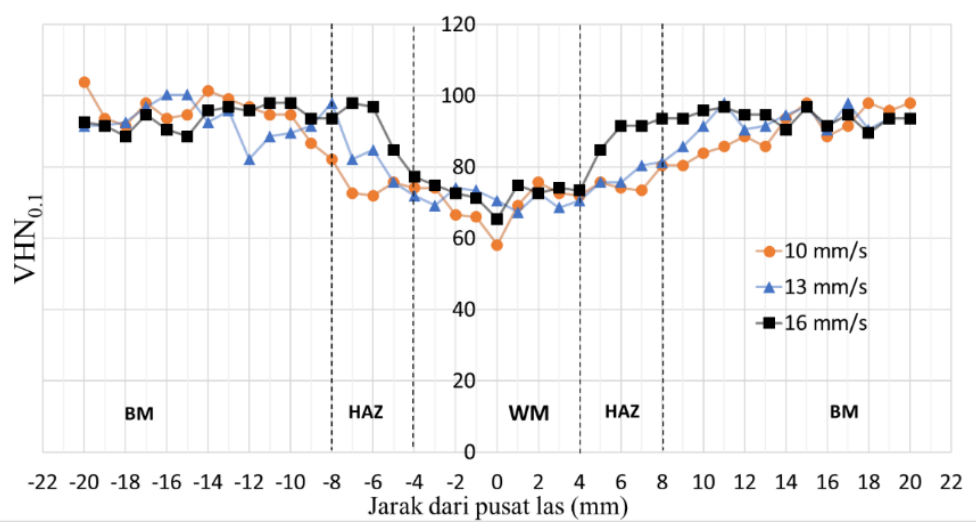

Figure 9. Hardness value comparison

Table 4. Average hardness values

\begin{tabular}{cccc}
\hline \multirow{2}{*}{ Welding speed } & BM & HAZ & WM \\
\cline { 2 - 4 } & \multicolumn{2}{c}{ Average Vickers hardness value } \\
\hline $10 \mathrm{~mm} / \mathrm{s}$ & 94.07 & 77.34 & 69.84 \\
$13 \mathrm{~mm} / \mathrm{s}$ & 93.10 & 83.11 & 70.94 \\
$16 \mathrm{~mm} / \mathrm{s}$ & 93.79 & 92.21 & 72.96 \\
\hline
\end{tabular}

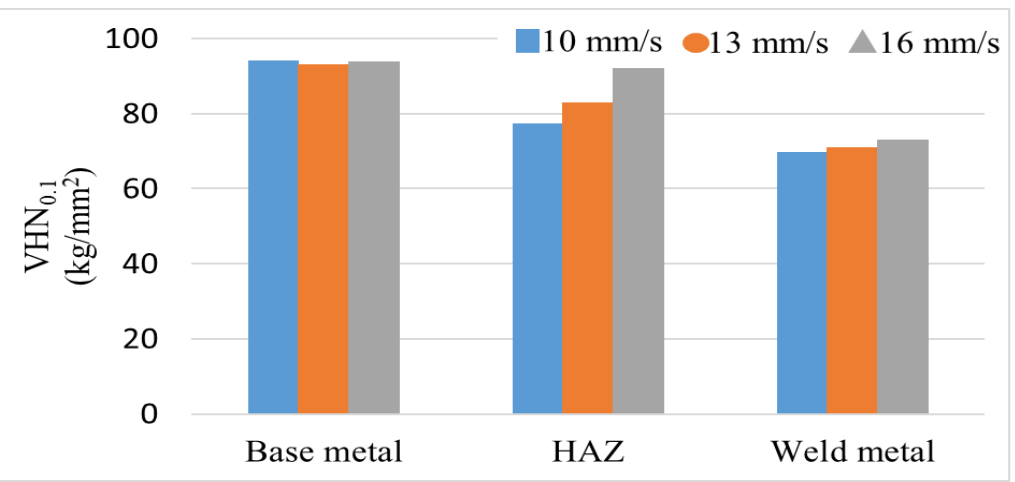

Figure 10. Comparison of average hardness values in BM, HAZ, and WM 
In Figure 10 it can be observed that the Vickers hardness value-distance to weld core curve for every weld variation had a similar trend line to another variation. The lowest hardness values were found in the WM, which increased in the HAZ and achieved maximums in the BM. The HAZ exhibited lower hardness values than the BM. Series $5 \mathrm{xxx}$ aluminum alloys are non-heat treatable, thus the strength cannot be increased by applying heat. The decrease in hardness value in the HAZ can be associated with microstructure. The HAZ had bigger grains than the BM, causing the strength to withstand dislocation to go down. The lowest hardness value in the WM, too, is tied to microstructure. Compared to the $\mathrm{BM}$ and HAZ, the WM had larger granular sizes giving it the lowest strength to withstand dislocation. The $16 \mathrm{~mm} / \mathrm{s}$ welding speed specimen, which received the smallest heat input, yielded the highest hardness value, while the $10 \mathrm{~mm} / \mathrm{s}$ welding speed specimen, which received the most heat input, did the lowest hardness value. Series 5xxx aluminum alloys can be subjected to work hardening, which can cause alteration to the microstructure. A rolling or work hardening process is a key factor that gives the BM greater hardness than the WM (Yazdipour dkk, 2011).

\section{Tensile Test}

The results of the tensile test per the ASTM-E8 are provided in Figure 11. The yield strength value of $292.52 \mathrm{MPa}$ and tensile strength value of $360.31 \mathrm{MPa}$ of the raw material were to be compared with the yield and tensile strength of the 2-layer MIG weld specimens. At the welding speed of $10 \mathrm{~mm} / \mathrm{s}$, the specimen had the greatest yield strength and tensile strength $(230,95 \mathrm{Mpa}$ and 281.07 $\mathrm{MPa}$, respectively), thus the maximum welding efficiency (welding efficiency $=$ the tensile strength of the welded material divided by the tensile strength of the raw material = $78 \%$ ). The specimens at the welding speeds of $13 \mathrm{~mm} / \mathrm{s}$ and $16 \mathrm{~mm} / \mathrm{s}$ had lower yield strength and tensile strength (Figure 11). The 2-layer MIG welding efficiency was indistinct from that of 1-layer MIG welding as studied by Mudjijana et al. (2017). Hence, the plate thickness of $3 \mathrm{~mm}$ is not suited for 2-layer welding.

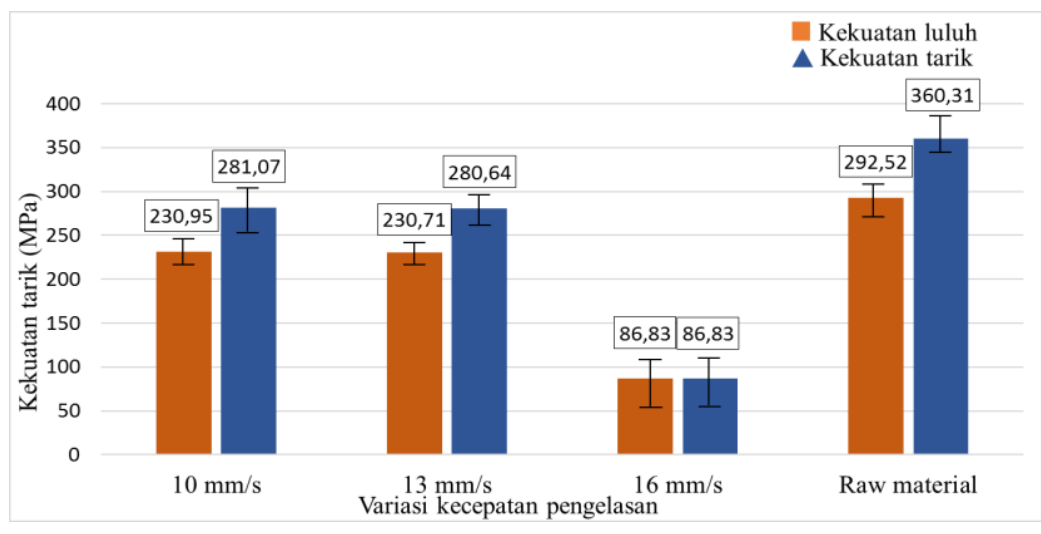

Figure 11. Tensile strength vs welding speed variation

\section{Potentiodynamic polarization corrosion test}

The results of the corrosion test with the potentiodynamic polarization method (potential (V) vs current density comparison $\left(\mathrm{A} / \mathrm{cm}^{2}\right)$ ) are presented in Figure 12. Through calculations, corrosion rates were obtained and are presented in Table 4. BM had the 
lowest corrosion rate, namely $0.253 \mathrm{~mm} /$ year. The specimen for the welding speed of 10 $\mathrm{mm} / \mathrm{s}$ produced a corrosion rate of 0.285 $\mathrm{mm} /$ year, $13 \mathrm{~mm} / \mathrm{s} 0.277 \mathrm{~mm} /$ year, and 16 $\mathrm{mm} / \mathrm{s} 0.450 \mathrm{~mm} /$ year.

The corrosion rate in the weld zone was higher than the base material, in which case, the corrosion rate in the weld zone would increase with welding speed. Al-Mg alloys have good resistance to corrosion (Wiryosumarto, 2000). Variation in heat input amount leads to variation in precipitate amount in WM, while variation in precipitate variation leads to variation in Ecorr and Icorr values in WM. The more precipitate amount in WM, the higher the Ecorr and Icorr values and the faster the corrosion rate. A defect in WM in the form of porosity also plays a role in the acceleration of the corrosion rate. Corrosion will attack the weakest region in which defects are found. Varying corrosion resistance rates across weld joint locations are dependent on the distribution, sizes, and types of precipitates and the chemical composition (Li et al., 2017).

Table 5. Corrosion rates of BM and 2-layer MIG welding result

\begin{tabular}{ccccc}
\hline Material & $\begin{array}{c}\text { Welding speed } \\
(\mathrm{mm} / \mathrm{s})\end{array}$ & $\mathrm{E}_{\text {corr }}(\mathrm{mV})$ & $\mathrm{I}_{\text {corr }}(\mu \mathrm{A})$ & $\begin{array}{c}\text { Corrosion rate } \\
(\mathrm{mm} / \text { year })\end{array}$ \\
\hline Base material & - & -743.14 & 22.34 & 0.25 \\
Weld zone & 10 & -733.91 & 25.12 & 0.29 \\
& 13 & -751.42 & 33.23 & 0.38 \\
\hline
\end{tabular}

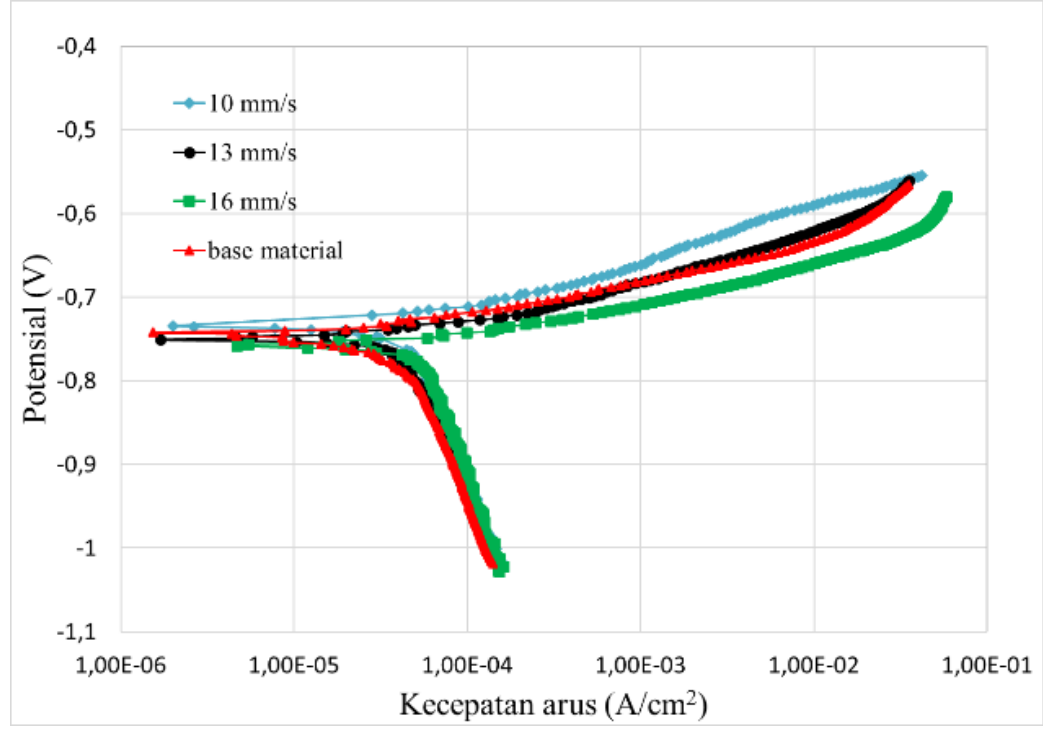

Figure 12. Potential (V) vs current density $\left(\mathrm{A} / \mathrm{cm}^{2}\right)$

\section{Conclusion}

Based on the testing on the 2-layer MIG welding joints obtained at different welding speeds $(10,13,16 \mathrm{~mm} / \mathrm{s})$, it can be concluded that (1) an increase in the welding speed causes a decrease in the maximum temperature achieved, leading to lowered heat input received by the specimen and lowered tensile strength; (2) an increase in the welding speed causes an increase in the hardness in the $\mathrm{HZ}$ and BM; and (3) an increase in the welding speed causes a decrease in the resistance to 
corrosion in the weld zone, in which case, the $\mathrm{BM}$ has better corrosion resistance than the WM.

\section{Acknowledgements}

Gratitude is due to the Minister of Research, Technology, and Higher Education, who have funded this research under the UGM PDD contract no. 1769/UN1/DITLIT/DIT-LIT/LT/2018, the Department of Mechanical and Industrial Engineering of the Faculty of Engineering, UGM, for the opportunity, and Mr. Ekak, Mr. Sunhaji, Mr. Yasin, and Mr. Arief, for assisting with this research.

\section{References}

Ashby, M. F. dan Jones, D. R. H., 2013, Engineering Materials 2: An Introduction Microstructures and Processing, 4thed, Butter-worth-Heinemann, p. 190.

ASME, 2001, Materials Part C - Specifications for Welding Rods, Electrodes, and Filler Metals, ASME, New York.

ASTM, 2009, E8/E8M-09, Standard Test Method for Tension Testing of Metallic Materials, ASTM International.

ASTM, 2015. E407-07 (Reapproved 2015), Standard Practice for Micro-etching Metals and Alloys, ASTM International.

Haelsig, A., Kusch, M., Mayr, P., 2012, New Findings on The Efficiency of Gas Shielded Arc Welding. 56, pp. 98-104.

Kim, S-J., Kim, S-K., Park, J-C., 2010, The Corrosion and Mechanical Properties of Al Alloy 5083-H116 in Metal Inert Gas Welding Based on Slow Strain Rate Test. Surface \& Coatings Technology, 205, pp. S73-S78.

Li, S., Dong, H, Shi, L., Li, P., Fe., Y. 2017, Corrosion Behavior and Mechanical Propertieso of $\mathrm{Al}-\mathrm{Zn}-\mathrm{Mg}$ Aluminum Alloy Weld, Corrosion Science, 123, pp. 243-255.

Mudjijana, Ilman, M.N., Iswanto, P.T., 2017, Karakterisasi Pengaruh Kecepatan Las pada Pengelasan MIG AA 5083 H116 dengan Elektroda ER 5356, POROS, Volume 15 Nomor 1, pp. 26-34.

Wiryosumarto, H., 2000, Teknologi Pengelasan Logam, PT Pradnya Paramita, Jakarta.

Yazdipour, A.R., Shafiei, L., Aval, H.J., 2011, An Investigation of The Microstructures and Properties of Metal Inert Gas and Friction Stir Welds in Aluminum Alloy 5083, Sadhana, Vol. 36, pp.50 